\title{
Impact analysis of new metro line opening on passenger flow: A case study of Shenzhen
}

\author{
Zihao Li ${ }^{1,2}$, Yufeng Zhou' ${ }^{1}$, Zhongwen Li ${ }^{3}$, Wei Zhou'3 , Maohua Zhong1,a \\ 1 Institute of Public Safety Research, Department of Engineering Physics, Tsinghua University, Beijing 100084, China \\ 2 Beijing Key Laboratory of City Integrated Emergency Response Science, Beijing 100084, China \\ ${ }^{3}$ Shenzhen Metro Co., Ltd, Shenzhen 518026, China
}

\begin{abstract}
Metro systems, as major components of the transit system, have been significantly developed in recent years and an increasing number of new metro lines are operated in China. This paper not only analyses the short and long-term impact of new lines opening on passenger flow from passenger volume, section imbalance coefficient, direction imbalance coefficient and travel time, with the help of passenger flow data from September 2016 to October 2018 in Shenzhen but also proposes a new method to identify the growth period of the transfer flow in new lines. The result shows that the new metro lines cannot solve the problems of imbalance and congestion in Shenzhen Metro. it increased the travel time in the morning and evening peak, but largely decreased the travel time in the off-peak period. Additionally, there is a significant positive correlation between the length of the growth period and the number of transfer stations of the transfer line.
\end{abstract}

\section{Introduction}

With the rapid development of the economy, cities are constantly expanding which increases the pressure on round traffic. Therefore the demand for a multi-model, intelligent, modern, fast and safe transportation system is increasing. The metro system is a mean of public transportation with multiple benefits, such as large capacity, high speed, safety, punctuality, energy-saving, environmental protection, and etc. It plays an important role in the urban transit system and gradually become the main mode of public transportation for people. In China, the total length of the metro system is about 5766.6 kilometers. There are 36 cities owned metro system and 24 of them have formed the metro networks, such as Beijing, Shanghai, Guangzhou, and Shenzhen, etc.

With the opening of new metro lines, great changes have taken place in the network topology, connectivity, and accessibility of the metro system. The volume of passenger flow increased and the passenger flow appeared to exhibit unexpected patterns. However, administrators and researchers lack quantitative understandings of the impact of new metro lines opening on passenger flows especially during peak hours. They are also unfamiliar with the growth patterns of passenger flows in different lines. Characteristics of passenger flow are important for transport operators to provide better service and management, such as timetable improvement, transit planning, and station management. Especially, with the continuous expansion of the metro network, it will be helpful for operation optimization to study the change and growth pattern of passenger flow after the opening of new lines.

In this study, a comprehensive analysis of metro passenger flow and travel time are investigated on the basis of Automatic Fare Collection (AFC) data from Shenzhen, China. The short and long-term impacts of new metro lines on passenger flow are analyzed on the level of the whole metro network by different characteristics of passenger flow and temporal distributions of passenger flow. The outline of this paper is as follows, Section 2 presents a review of previous studies about the implementation of smart card data and the impact of new line opening. Data used in this study are described in Section 3. The short and long-term impact of new metro lines on networks and change patterns of transfer passenger flow investigated in Section 4 and 5. Conclusions are presented in the last section.

\section{Literature Review}

\subsection{Implementation of Smart Card Data}

In the past, the methods to collect the data on transit behavior have mainly relied on conventional behavioral surveys such as travel diary surveys[1,2], panel surveys, and travel surveys with tracking devices[3,4]. Nowadays, smart card data provide continuous and long-term travel information such as travel ID, boarding time/location,

\footnotetext{
a Corresponding author: mhzhong@tsinghua.edu.cn
} 
and alighting time/location. Based on that, researchers can analyze travel patterns of the metro system, such as each traveler's trip frequency, travel time and distance, peak hour factor, and so on. Several studies have developed methods that utilized smart card data to improve transit management and planning. Trépanier et al.[5] presented a model to estimate the destination of each individual boarding by using smart card data. Asakura et al.[6] estimated boarding trains of railway passengers by using smart card data and evaluated the effects of changes in train operations. They compared passengers' travel choice behavior before and after the railway company altered the train timetable. Ma et al.[7]developed an efficient data mining method to demonstrate the temporal travel patterns and the pattern regularity for transit riders in Beijing. Gan et al.[8] explored the relationship between daily ridership patterns and characteristics of stations. Moreover, some researchers found that the nature of regularity is considerably more complex, varying within and between individuals on day-to-day basis [9], influenced by socioeconomic status and land use activity types[10], trip chaining[11], changes in weather[12], simple ad hoc requirements, such as managing congestion through physical means and the change of topology of metro system.

\subsection{Impact of New Metro Line}

The opening of the new line will change and influence many aspects from the topology of the network, commuting connectivity of passenger flow to the regional economy and transportation. Some researchers analyzed the impact of the new metro line on the economy. Agostini et al.[13] verify the new metro line has a positive impact on the housing units with closer access to the metro and the price increase depending on the distance from the house to the nearest station. The same result was obtained by Dorantes et al.[14] in Madrid. Mejia-Dorantes et al.[15] uses spatial statistical techniques and real-world data to evaluate the effects of Madrid's metro line 12 expansion on business location patterns, which indicate that the pattern of economic activity location is related to urban accessibility, agglomeration, and economies of scale. Other researchers focused on the impact of the new metro line on transportation. Vuk[16] analyzes the transport impact of the metro based on traffic counts, panel interviews and the forecast model. The result showed that most of the modal shift to the metro derives from bus passengers and $8 \%$ to $14 \%$ is attributable to car users. Golias[17] evaluates the impacts of the construction of a new metro system as the impacts pertain to traveler behavior and mode choice. He indicates that the increase in travel time and cost for the auto would increase the demand for the metro, but not as much for the bus. The prevalence of big data offers an opportunity to conduct relevant demand analyses. $\mathrm{Fu}$ and $\mathrm{Gu}[18]$ use the smart card data of the metro system from Nanjing, China to show that the new metro line influences passenger flow, travel time and travel time reliability in the metro network. At the same time, the new line opening has different impacts on different categories of commuters. Wang[19] analyze the mechanism of influence produced by a newly constructed urban rail transit line on urban public traffic network and build a prediction model on passenger flow volume. Liu[20] utilize AFC data to develop proxy variables and propose multivariate regression models to explore station-level ridership growth with network topology change and surrounding land use development.

\section{Study Area and Data Collection}

Shenzhen is the special economic zone and one of the four first-tier cities in China with a population of about 125 million at the end of 2017. In the past decade, the Shenzhen metro network expanded rapidly from a single line with a length of 14.83 kilometers in 2004 to eight lines with a length of 292.6 kilometers in 2018. The overview of the Shenzhen metro network is shown in Fig 1. Line 7 and Line 9 of the Shenzhen metro system were opened on 28 October 2016 at the same time. After the opening of Line 7 and Line 9, Shenzhen metro is the fifth-largest urban rail transit system in China with 199 stations and 28 transfer stations, and the average daily ridership in 2019 is about 5.85 million.

In order to explore the impact of the new metro lines (i.e., Line 7 and Line 9) on the characteristics of passenger flow and travel time in the whole network, the data used in this study are the record of Automatic Fare Collection System (AFC) data in Shenzhen from September 2016 to October 2018. AFC data contain complete boarding and alighting records (including location and time) of each passenger as shown in Table 1, transfer records of each transfer station and passenger record of each metro section. Data for the two years are utilized because the two years data cover not only the period before and after the opening of Line7 and Line9, but also the development period of passenger flow on the new line.

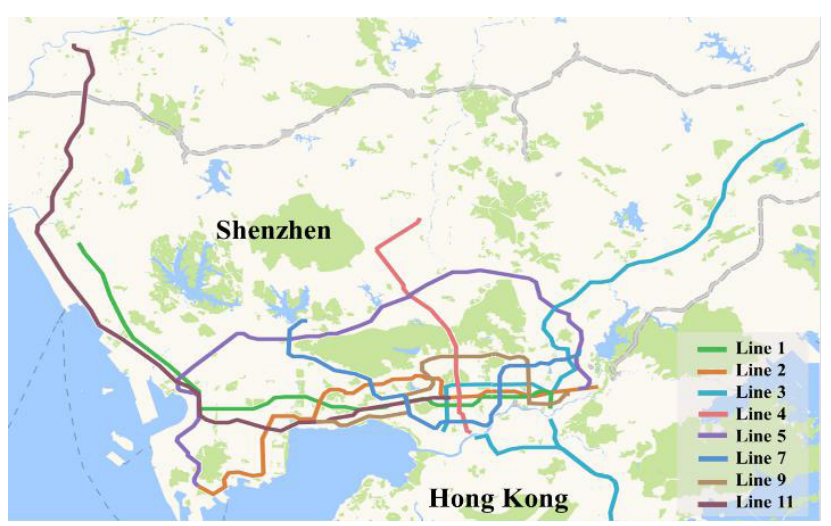

Figure 1. The overview of the Shenzhen metro network in 2019

Table 1. Example of AFC data used in this study

\begin{tabular}{ccccc}
\hline \multirow{2}{*}{ ID } & $\begin{array}{c}\text { Boarding } \\
\text { Time }\end{array}$ & $\begin{array}{c}\text { Boarding } \\
\text { Station }\end{array}$ & $\begin{array}{c}\text { Alighting } \\
\text { Time }\end{array}$ & $\begin{array}{c}\text { Alighting } \\
\text { Station }\end{array}$ \\
\hline \multirow{2}{*}{20000511} & $2016 / 11 / 17$ & \multirow{2}{*}{ Xiameiling } & $\begin{array}{c}2016 / 11 / 17 \\
08: 59: 46\end{array}$ & Yannan \\
\hline
\end{tabular}




\section{Impact of the New Metro Line on Passenger Flow}

In this section, this research compares the boarding/alighting passenger flow, the direction imbalance coefficient, the section imbalance coefficient, transfer coefficient, travel time distribution in the morning/evening peak (the morning peak is at 7 a.m. to 9 a.m. and the evening peak is at 18 p.m. to 20 p.m.) and the average travel time in the time of day one month before and after the opening of new lines to quantitatively analyze the impact of the opening of new lines.

The Direction Imbalance Coefficient (DIC) [21] is the ratio of two times of the maximum section passenger volume on the line $l$ to the sum of the upstream maximum section passenger volume $U_{l s}^{\max }$ and the downstream maximum section passenger volume $U_{l x}^{\max }$ in the period of $t$. This value represents the balance of passenger flow in the upstream and downstream direction of a line. The larger the value, the passenger flow more concentrated is in one direction, the more likely it is to have crowed.

$$
\varepsilon_{l}=\frac{2 \times \max \left(U_{l s}^{\max }, U_{l x}^{\max }\right)}{U_{l s}^{\max }+U_{l x}^{\max }}
$$

The Section Imbalance Coefficient (SIC) [21] is the ratio of the product of the maximum one-way section passenger volume of the line and the number of line sections to the sum of all section passenger volume in the period of $t$. The value represents the passenger flow distribution of sections in a line. The large the values, the passenger flow more concentrated is in a section.

$$
\delta_{l}=\frac{U_{l}^{\max } \times k_{l}}{\sum_{k} U_{l}^{k}}
$$

The Transfer Coefficient (TC) [21] is the ratio of the transfer passenger volume $T_{l}$ to the sum of the boarding passenger volume $E_{l}$, the alighting passenger volume $O_{l}$, and the transfer passenger volume $T_{l}$. This value represents the proportion of transfer passenger flow in the sum of passenger flow. The large the value, the greater the transport pressure is at the transfer station.

$$
\alpha_{l}=\frac{T_{l}}{T_{l}+E_{l}+O_{l}} \times 100 \%
$$

As shown in Fig 2, the distribution of passenger flow with obvious double peaks in a working day and the arrival time of the morning and evening peak have little change. The morning peak is more concentrated than the evening peak passenger flow. The boarding/alighting passenger at the morning peak attracted around 4.2 thousand passengers per 15 minutes more than before, an increase of $6.8 \%$ year-on-year. The boarding/alighting passenger at the off-peak period attracted around 3.7 thousand passengers per 15 minutes more than before, an increase of $15.6 \%$ year-on-year. The boarding/alighting passenger at the evening peak attracted 8.9 thousand passengers per 15 minutes more than before, an increase of $15.3 \%$.

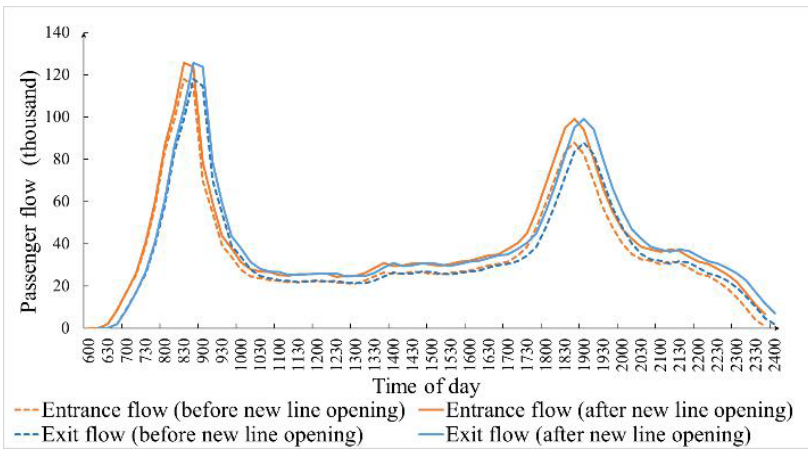

---Exit flow (before new line opening) - Exit flow (after new line opening)

Figure 2. Impact of new lines opening on alighting and boarding passenger flow on weekdays

In Fig 3, the increase of weekend passenger flow distributed in the period after 9 a.m. evenly. Before 9 a.m., the opening of new lines has little impact on passenger flow. However, in the interval from 9 a.m. to 12 a.m., the difference in passenger flow before and after the opening of new lines gradually increased, reaching the maximum at the evening peak. The passenger flow increased by 8.6 thousand passengers per 15 minutes more than before and an increase of $22.9 \%$. In the time of 19 p.m. to 24 p.m., the difference was decreased with the growth of 7.2 thousand passengers per hour more than before.

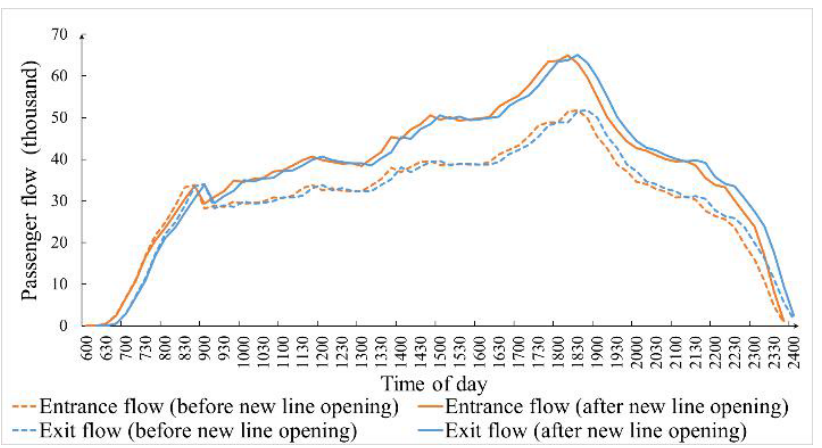

Figure 3. Impact of new lines opening on alighting and boarding passenger flow on weekend

Table 2 shows the changing pattern of the SIC after the opening of new lines. In the upstream direction, the imbalanced coefficient of Line1 and Line4 increases at the morning peak but decreased at the evening peak. That shows that Line1 and Line4 have a strong commuting function and new lines opening intensify the direction imbalance of these two lines. The SIC of Line 2 on both directions has been reduced but the max passenger flow has been increased indicating that the opening of new lines can better alleviate the imbalance in Line2. The SIC of Line3, Line5, and Line11 have a large increase in both the upstream and downstream directions and both the morning and evening peak showing that new lines opening increased the transport pressure in those lines. Because those metro lines are mainly responsible for transporting passengers between rural and urban areas, more metro station attracts many travelers for whom it was inconvenient to take the metro in the before.

Since the SIC is a dimensionless number, to analyze the impact of the opening of the new line, the maximum 
section passenger volume should be compared. For all the metro lines, the growth rate of the morning peak is high with an increased rate of $[1.87 \%, 19.15 \%]$. Therefore, the opening of new lines will not relieve the crowding of the morning peak. At the evening peak, the maximum section passenger volume of Line1, Line2, Line4 has been reduced. At the rest time of the evening peak, the increasing rate is around $[0.05 \%, 12.32 \%]$, which is lower than that of the morning peak. Therefore, new lines opening attracted more passengers in the morning peak rather than the evening peak.

Regarding the DIC (see Table 3), no matter in the morning or evening peak, the opening of new lines increased the Average Passenger Volume (APV) of most lines, but it does not affect the maximum passenger flow direction. In the morning peak, for Line1, Line3 and Line4, Line11 the direction imbalance is aggravated. In the morning peak of Line 2 and Line5, the imbalance coefficient is declined but the average passenger volume is inclined, indicating that new lines can better improve the utilization rate both upstream and downstream. In the evening peak, as to Line1, Line2, Line3, and Line4, new lines also aggravate the transport pressure of existing lines. However, in the evening peak of Line5, the opening of new lines can better solve the imbalance of direction with the $6.34 \%$ increase in passenger volume, which means both the upstream and downstream passenger volumes have grown. So administrators should pay more attention to mass passenger volume incidents. At the same time, new lines can reduce the transport pressure of the Line11 in the evening peak since the number of passenger flow has decreased.

As shown in Fig 4, from the distribution of passenger flow volume and passenger flow rate, it can be seen that the volume of passengers has increased in each time interval after the opening of new lines, especially in the interval of $[600 \mathrm{~s}, 2700 \mathrm{~s}]$. However, the proportion of passengers in a short time (600s to $1200 \mathrm{~s})$ and the proportion of passengers in a long time (greater than 3600s) declined slightly. The proportion of passengers in the interval of $[1500 \mathrm{~s}, 3000 \mathrm{~s}]$ increased. As shown in Fig 5 , in the evening peak, the changing pattern is similar to that in the morning peak and the volume of passenger flow also increases in every time period. But the maximum passenger flow rate appears in a shorter time interval. Hence, with the benefit of enhancement of accessibility and connectivity, the opening of new lines reduced the ratio of short-time and long-time passengers.

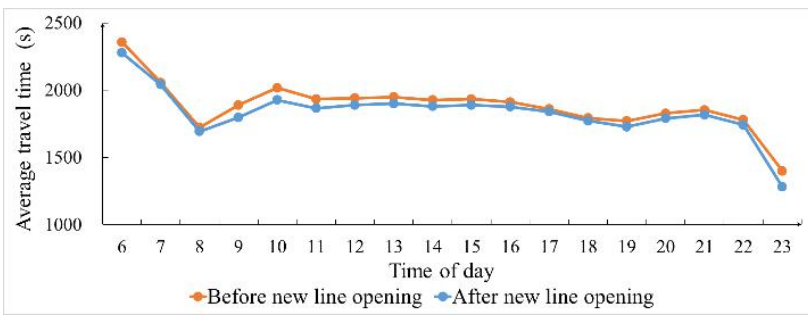

Figure 6. Impact of new lines opening on average travel time in the time of day

As shown in Fig 6, the average travel time of whole networks was shortened by 51 seconds due to the opening of a new line opening, mainly from before and after the morning peak, off-peak period, and after evening peak. However, there is little impact on morning peak and evening peak. This shows that the opening of new lines has not saved travelers' travel time in the morning and evening peak because even if the travel time is shortened, due to the increase in passenger volume, the waiting time and the time of boarding and alighting are increased.

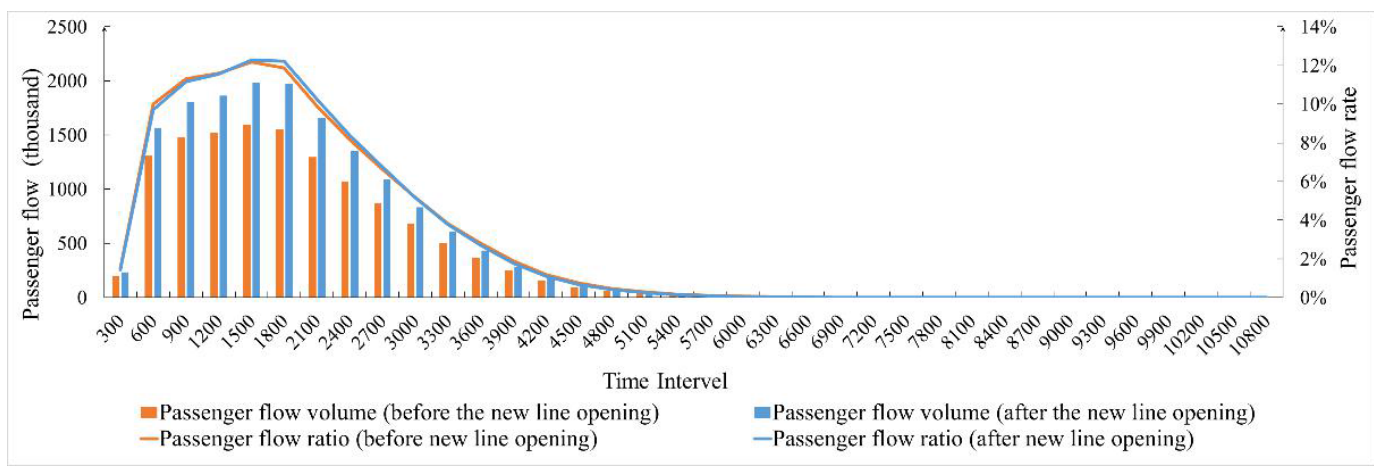

Figure 4. Travel time and travel time ratio distribution in the morning peak

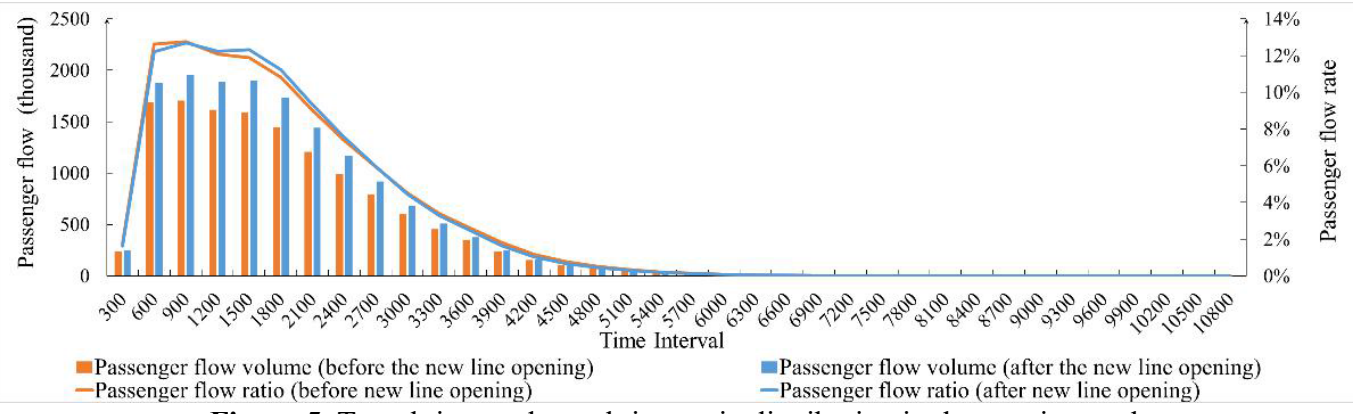

Figure 5. Travel time and travel time ratio distribution in the evening peak 
Table 2. The change rate of SIC and max passenger flow of the section after new lines opening

\begin{tabular}{|c|c|c|c|c|c|c|c|c|c|}
\hline & & \multicolumn{4}{|c|}{ Upstream Direction } & \multicolumn{4}{|c|}{ Downstream Direction } \\
\hline & & \multicolumn{2}{|c|}{ Morning Peak } & \multicolumn{2}{|c|}{ Evening Peak } & \multicolumn{2}{|c|}{ Morning Peak } & \multicolumn{2}{|c|}{ Evening Peak } \\
\hline & & SIC & $\begin{array}{c}\text { Max } \\
\text { passenger flow }\end{array}$ & SIC & $\begin{array}{c}\text { Max } \\
\text { passenger flow }\end{array}$ & SIC & $\begin{array}{c}\text { Max } \\
\text { passenger flow }\end{array}$ & SIC & $\begin{array}{c}\text { Max } \\
\text { passenger flow }\end{array}$ \\
\hline \multirow{3}{*}{ Line 1} & Before & 1.71 & 4752 & 1.95 & 3495 & 2.06 & 3407 & 1.53 & 4172 \\
\hline & After & 1.86 & 5665 & 1.88 & 3522 & 2.05 & 3661 & 1.61 & 4695 \\
\hline & Rate & $8.39 \%$ & $18.28 \%$ & $-3.36 \%$ & $-0.24 \%$ & $-0.63 \%$ & $6.11 \%$ & $4.63 \%$ & $11.73 \%$ \\
\hline \multirow{3}{*}{ Line2 } & Before & 1.87 & 1224 & 2.22 & 2123 & 2.35 & 2433 & 1.81 & 1323 \\
\hline & After & 1.86 & 1466 & 2.16 & 2327 & 2.31 & 2816 & 1.65 & 1332 \\
\hline & Rate & $-0.47 \%$ & $19.15 \%$ & $-2.48 \%$ & $8.53 \%$ & $-1.62 \%$ & $13.85 \%$ & $-8.96 \%$ & $-1.44 \%$ \\
\hline \multirow{3}{*}{ Line3 } & Before & 2.09 & 4822 & 1.54 & 1679 & 1.53 & 1236 & 1.99 & 4521 \\
\hline & After & 2.19 & 5780 & 1.54 & 1716 & 1.57 & 1296 & 2.04 & 4964 \\
\hline & Rate & $4.66 \%$ & $18.63 \%$ & $0.05 \%$ & $1.02 \%$ & $2.44 \%$ & $4.44 \%$ & $2.72 \%$ & $8.77 \%$ \\
\hline \multirow{3}{*}{ Line4 } & Before & 1.54 & 5160 & 1.33 & 1475 & 1.39 & 1232 & 1.52 & 4976 \\
\hline & After & 1.58 & 5971 & 1.26 & 1399 & 1.35 & 1260 & 1.58 & 5555 \\
\hline & Rate & $2.92 \%$ & $13.95 \%$ & $-5.24 \%$ & $-5.66 \%$ & $-2.75 \%$ & $1.87 \%$ & $3.55 \%$ & $10.61 \%$ \\
\hline \multirow{3}{*}{ Line5 } & Before & 1.62 & 2744 & 1.83 & 2900 & 1.92 & 2921 & 1.60 & 2641 \\
\hline & After & 1.67 & 3173 & 1.90 & 3283 & 1.91 & 3421 & 1.61 & 2858 \\
\hline & Rate & $2.77 \%$ & $13.24 \%$ & $3.53 \%$ & $12.32 \%$ & $-0.44 \%$ & $14.90 \%$ & $0.61 \%$ & $6.51 \%$ \\
\hline \multirow{3}{*}{$\begin{array}{c}\text { Line } 1 \\
1\end{array}$} & Before & 1.68 & 1862 & 1.59 & 906 & 1.66 & 663 & 1.63 & 1943 \\
\hline & After & 1.75 & 2208 & 1.68 & 989 & 1.78 & 768 & 1.71 & 2094 \\
\hline & Rate & $4.24 \%$ & $15.83 \%$ & $5.63 \%$ & $8.08 \%$ & $7.06 \%$ & $14.20 \%$ & $4.78 \%$ & $6.67 \%$ \\
\hline
\end{tabular}

Table 3. The change rate of DIC, APV, and max passenger flow direction of the section after new lines opening

\begin{tabular}{|c|c|c|c|c|c|c|c|}
\hline & & \multicolumn{3}{|c|}{ Morning Peak } & \multicolumn{3}{|c|}{ Evening Peak } \\
\hline & & Coefficient & APV & Direction & Coefficient & APV & Direction \\
\hline \multirow{3}{*}{ Line1 } & Before & 1.16 & 2644 & $\mathrm{Up}$ & 1.09 & 2671 & Down \\
\hline & After & 1.21 & 2984 & Up & 1.15 & 2881 & Down \\
\hline & Rate & $4.23 \%$ & $11.09 \%$ & & $2.59 \%$ & $7.06 \%$ & \\
\hline \multirow{3}{*}{ Line2 } & Before & 1.30 & 959 & Down & 1.21 & 940 & Up \\
\hline & After & 1.30 & 1149 & Down & 1.26 & 1067 & $\mathrm{Up}$ \\
\hline & Rate & $-0.48 \%$ & $18.22 \%$ & & $4.08 \%$ & $11.77 \%$ & \\
\hline \multirow{3}{*}{ Line3 } & Before & 1.54 & 2257 & Up & 1.45 & 2253 & Down \\
\hline & After & 1.60 & 2607 & Up & 1.48 & 2417 & Down \\
\hline & Rate & $3.36 \%$ & $14.14 \%$ & & $2.01 \%$ & $6.34 \%$ & \\
\hline \multirow{3}{*}{ Line4 } & Before & 1.57 & 3268 & Up & 1.52 & 3204 & Down \\
\hline & After & 1.62 & 3695 & Up & 1.58 & 3470 & Down \\
\hline & Rate & $2.95 \%$ & $11.62 \%$ & & $4.59 \%$ & $7.36 \%$ & \\
\hline \multirow{3}{*}{ Line5 } & Before & 1.06 & 1655 & Down & 1.07 & 1645 & Up \\
\hline & After & 1.06 & 1867 & Down & 1.08 & 1770 & Up \\
\hline & Rate & $-0.62 \%$ & $10.77 \%$ & & $-1.39 \%$ & $6.34 \%$ & \\
\hline \multirow{3}{*}{ Line11 } & Before & 1.44 & 1083 & Up & 1.35 & 1404 & Down \\
\hline & After & 1.45 & 1221 & Up & 1.35 & 1209 & Down \\
\hline & Rate & $0.91 \%$ & $11.14 \%$ & & $1.73 \%$ & $-9.23 \%$ & \\
\hline
\end{tabular}

\section{Growth Pattern of passenger flow of new lines}

The growth period and stabilization period of the new lines are identified by the changing pattern of $\mathrm{TC}$, as shown in Fig 7, 8, 9, 10. Because of the influence of external factors, such as holiday and weather, and the pattern of TC curve, this research performs a logarithmic curve fitting to the changing pattern of TC and obtained the formula and values of $\mathrm{R}^{2}$ shown in Table 4 and Table 5. The $\mathrm{X}$ in the formula represents the number of months after new lines opening. In this study, the change rate of curve slope is less than or equal to -0.0001 taking as the criterion for judging whether it is a stabilization period or not, because under such conditions, the TC is nearly stable. Therefore, the passenger flow stabilization period of different lines can be obtained by calculating the second derivative of the fitting curve.

The calculation result of the growth period is shown in Table 6 . The average growth period of Line 7 is generally longer than the average growth period of Line 9. By analyzing the correlation between the length of the growth period, the length of transfer lines and the number of transfer stations in a line, it is found that there is a significant positive correlation between the length of the growth period and the number of transfer stations in the transfer line. For instance, the length of the growth period of Line7 to Line1 is related to the number of transfer stations of Line1. Moreover, there is no significant correlation between the length of the growth period and the length of transfer lines.

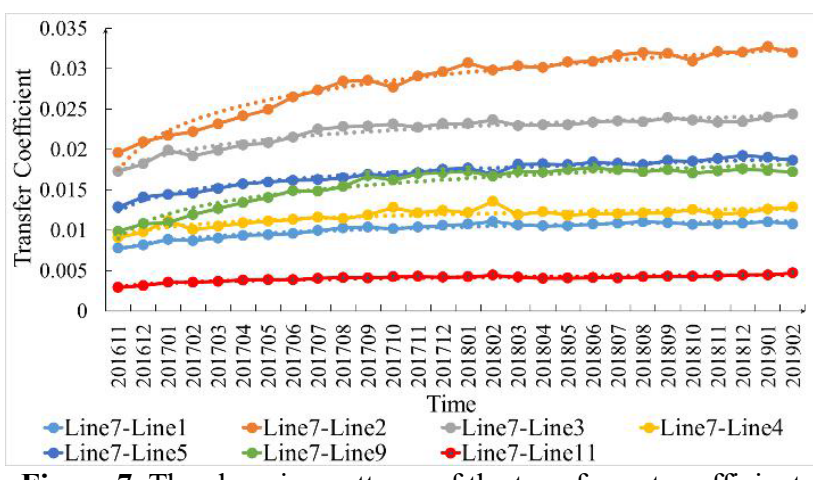

Figure 7. The changing patterns of the transfer-out coefficient on Line 7 


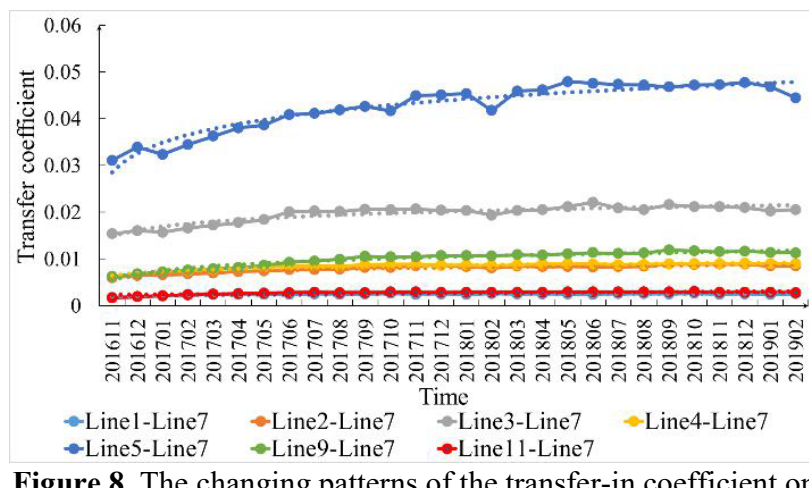

Figure 8. The changing patterns of the transfer-in coefficient on Line 7

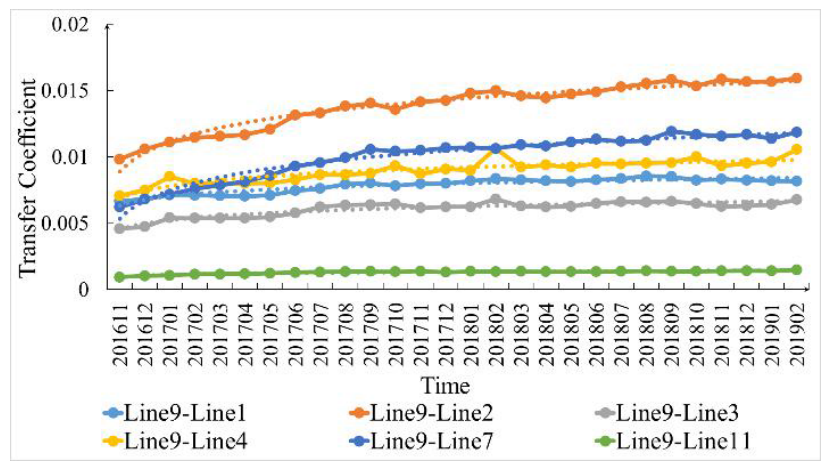

Figure 9. The changing patterns of the transfer-out coefficient on Line 9

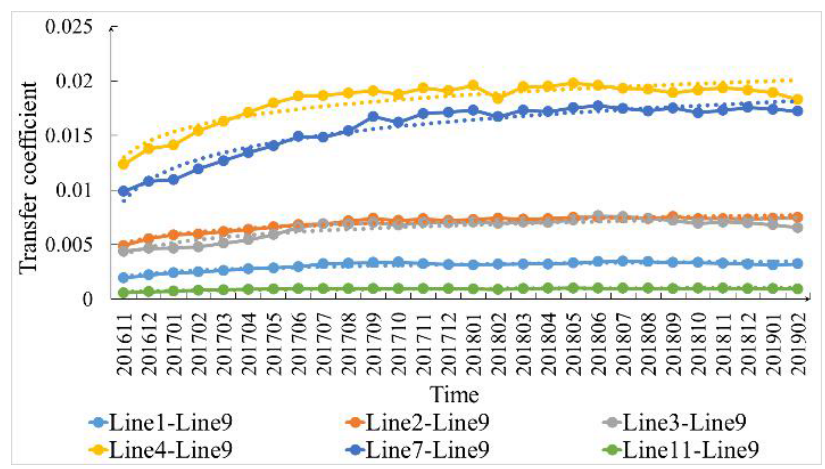

Figure 10. The changing patterns of the transfer-in coefficient on Line 9
As shown in Fig. 11, the passenger flow grows with time in the morning peak, while the total passenger volume in 2018 has a huge increase. With the time pass, the proportion of passenger flow within 600 s does not change much. In the interval of $[600 \mathrm{~s}, 900 \mathrm{~s}]$, the proportion of passenger flow slowly increases. In the interval of [900s, 2100 s], the proportion of passenger flow grow slowly in 2017 and decline hugely by $12 \%$ in 2018 , while the proportion of passenger flow in [2100s, 6000s] increase slightly. As shown in Fig. 12, the change of passenger flow and passenger flow rate in the evening peak are similar to that in the morning peak. But in the interval of [900s, 2100s], the rate of passenger flow gradually decreased. The aforementioned change patterns are because, after the opening of the new line, the accessibility and operational efficiency are improved, thus reducing the travel time of passengers and increasing the maximum travel distance.

In the long term shown in Fig. 13, the average travel time of the metro network has increased slightly at the morning peak and the evening peak. The travel time has significantly decreased in the off-peak period by nearly 40 seconds. This phenomenon is because, with the development of the city scale and the opening of the new metro line, passengers are more inclined to travel by metro. In the morning and evening peak, a large volume of passenger flow will cause congestion in the station and increase the travel time. However, in the off-peak period, with the benefit of more route selection and enhancement of accessibility, people can reduce their travel time.

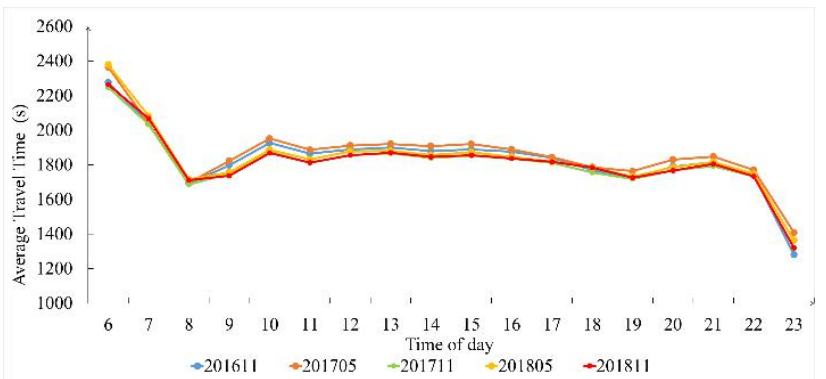

Figure 13. Long term impact of new lines opening on average travel time in the time of day

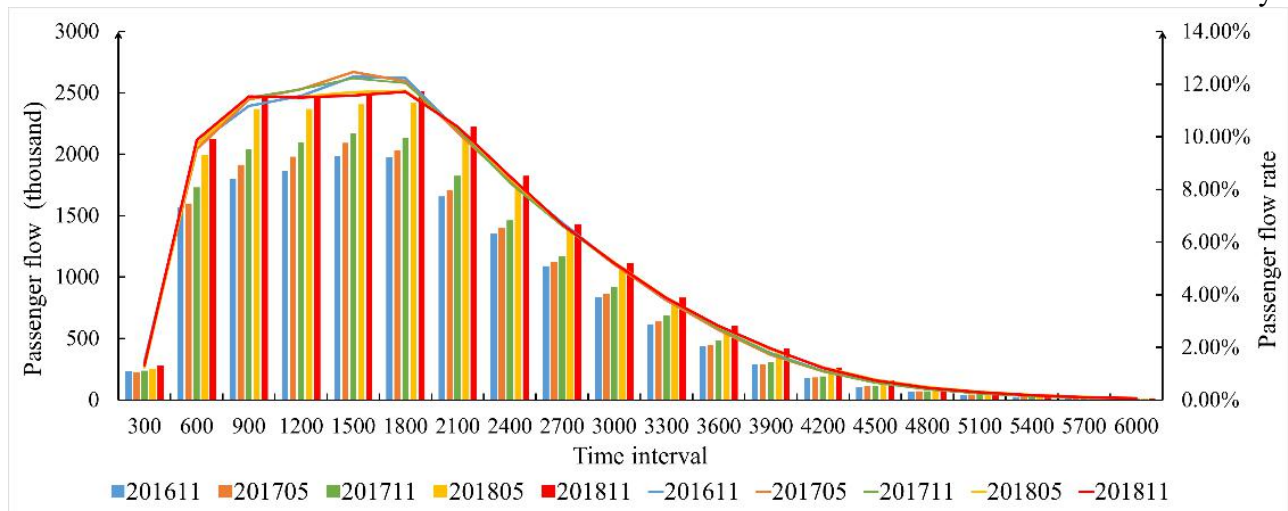

Figure 11. Travel time and travel time ratio distribution in the long term on the morning peak 


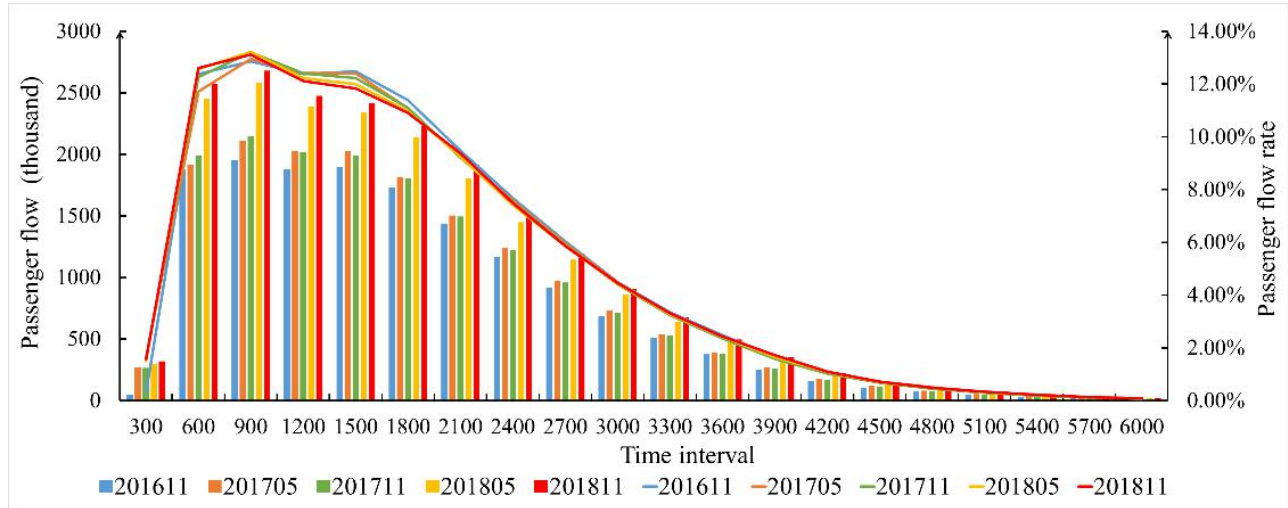

Figure 12. Travel time and travel time ratio distribution in the long term on the evening peak

Table 4. Result of the fitting curve of transfer passenger flow on Line 7

\begin{tabular}{|c|c|c|c|c|c|}
\hline Line & Fitting Curve & $\mathbf{R}^{2}$ & Line & Fitting Curve & $\mathbf{R}^{2}$ \\
\hline Line7-Line1 & $0.0011 \ln (\mathrm{x})+0.008$ & 0.9427 & Line1-Line7 & $0.0002 \ln (\mathrm{x})+0.002$ & 0.6803 \\
\hline Line7-Line2 & $0.0045 \ln (\mathrm{x})+0.017$ & 0.9562 & Line2-Line7 & $0.0009 \ln (\mathrm{x})+0.006$ & 0.9301 \\
\hline Line7-Line3 & $0.0021 \ln (x)+0.017$ & 0.9359 & Line3-Line7 & $0.002 \ln (\mathrm{x})+0.015$ & 0.8426 \\
\hline Line7-Line4 & $0.001 \ln (\mathrm{x})+0.009$ & 0.764 & Line4-Line7 & $0.0008 \ln (x)+0.006$ & 0.9256 \\
\hline Line7-Line5 & $0.0027 \ln (\mathrm{x})+0.009$ & 0.932 & Line5-Line7 & $0.0058 \ln (\mathrm{x})+0.029$ & 0.9113 \\
\hline Line7-Line9 & $0.0019 \ln (\mathrm{x})+0.012$ & 0.9635 & Line9-Line7 & $0.0019 \ln (\mathrm{x})+0.005$ & 0.9581 \\
\hline Line7-Line11 & $0.0004 \ln (\mathrm{x})+0.003$ & 0.89 & Line11-Line7 & $0.0004 \ln (\mathrm{x})+0.002$ & 0.8533 \\
\hline
\end{tabular}

Table 5. Result of the fitting curve of transfer passenger flow on Line 9

\begin{tabular}{|c|c|c|c|c|c|}
\hline Line & Fitting Curve & $\mathbf{R}^{2}$ & Line & Fitting Curve & $\mathbf{R}^{2}$ \\
\hline Line9-Line1 & $0.0006 \ln (\mathrm{x})+0.006$ & 0.8648 & Line1-Line9 & $0.0004 \ln (\mathrm{x})+0.002$ & 0.8437 \\
\hline Line9-Line2 & $0.0021 \ln (x)+0.009$ & 0.9508 & Line2-Line9 & $0.0008 \ln (\mathrm{x})+0.005$ & 0.9315 \\
\hline Line9-Line3 & $0.0006 \ln (\mathrm{x})+0.005$ & 0.8497 & Line3-Line9 & $0.001 \ln (\mathrm{x})+0.004$ & 0.81 \\
\hline Line9-Line4 & $0.0009 \ln (\mathrm{x})+0.007$ & 0.7701 & Line4-Line9 & $0.0021 \ln (\mathrm{x})+0.013$ & 0.8372 \\
\hline Line9-Line7 & $0.0019 \ln (\mathrm{x})+0.005$ & 0.9581 & Line7-Line9 & $0.0027 \ln (\mathrm{x})+0.009$ & 0.932 \\
\hline Line9-Line11 & $0.0001 \ln (x)+0.001$ & 0.9233 & Line11-Line9 & $0.0001 \ln (x)+0.001$ & 0.7935 \\
\hline
\end{tabular}

Table 6. The growth period of transfer passenger in Line7 and Line9

\begin{tabular}{ccccccc}
\hline Line & $\begin{array}{c}\text { Growth period } \\
\text { (month) }\end{array}$ & Line & $\begin{array}{c}\text { Growth period } \\
\text { (month) }\end{array}$ & Line & $\begin{array}{c}\text { Growth period } \\
\text { (month) }\end{array}$ & $\begin{array}{c}\text { Line } \\
\text { (month) }\end{array}$ \\
\hline Line7-Line1 & 3 & Line1-Line7 & 1 & Line9-Line1 & 2 & Line1-Line9 \\
Line7-Line2 & 7 & Line2-Line7 & 3 & Line9-Line2 & 5 & Line2-Line9 \\
Line7-Line3 & 5 & Line3-Line7 & 5 & Line9-Line3 & 2 & Line3-Line9 \\
Line7-Line4 & 3 & Line4-Line7 & 3 & Line9-Line4 & 3 & Line4-Line9 \\
Line7-Line5 & 5 & Line5-Line7 & 8 & Line9-Line7 & 4 & Line7-Line9 \\
Line7-Line9 & 4 & Line9-Line7 & 4 & Line9-Line11 & 1 & Line11-Line9 \\
Line7-Line11 & 2 & Line11-Line7 & 2 & & & 1 \\
\hline
\end{tabular}

\section{Conclusion \& Discussion}

This study aims to analyze the impact of the new metro line opening on passenger flow from the characteristics of passenger flow and travel time. Using Shenzhen as a case study. The main conclusions are as following:

(1) In the short-term, the opening of new lines increases the boarding/alighting/transfer passenger volume in a short time and the attracting passenger flow in the evening peak is more than that in the morning peak. Moreover, the opening of new lines cannot solve the unbalance and congestion in Shenzhen metro, on the contrary, it increased the transport pressure on lines used for commuting.

(2) In the long term, the opening of new lines changes the ratio of passenger flow. The ratio of short- time and long-time passengers increased because, with the improvement of accessibility and operational efficiency of the metro, the opening of new lines reduce the travel time of passengers and increase the maximum travel distance. . Additionally, the average travel time has increased in the morning and evening peak but there is a significant decreased in the off-peak period.

(3) In the aspect of the growth period of new metro lines, there is a significant positive correlation between the length of the growth period and the number of transfer stations of the transfer line. Meanwhile, there is no significant correlation between the length of the growth period and the length of transfer lines. 


\section{Acknowledgments}

This paper was supported by the National Key R\&D Program of China (2018YFC0809900) and the National Outstanding Youth Science Foundation (51425404).

\section{References}

1. Pas, E. I., \& Koppelman, F. S. (1987). An examination of the determinants of day-to-day variability in individuals' urban travel behavior. Transportation, 14(1), 3-20.

2. Axhausen, K. W., Zimmermann, A., SchöNfelder, S., Guido Rindsfüser, \& Haupt, T. (2002). Observing the rhythms of daily life: a six-week travel diary. Transportation, 29(2), 95-124.

3. Murakami, E., \& Wagner, D. P. A. (1999). Can using global positioning system (GPS) improve trip reporting ?. Transportation Research Part C Emerging Technologies, 7(2-3), 149-165.

4. Asakura, Y. , \& Hato, E. (2004). Tracking survey for individual travel behavior using mobile communication instruments. Transportation Research Part C Emerging Technologies, 12(3), 273-291.

5. Martin Trépanier, Tranchant, N., \& Chapleau, R.. (2007). Individual trip destination estimation in a transit smart card automated fare collection system. Intellectual Transportation System. 11(1), 1-14

6. Asakura, Y., Iryo, T., Nakajima, Y., \& Kusakabe, T. (2012). Estimation of behavioral change of railway passengers using smart card data. Public Transport, 4(1), 1-16.

7. Xiaolei, M. A., WU, YaoJan, Wang, Y., Feng, C., \& Liu, J. (2013). Mining smart card data for transit riders' travel patterns. Transportation Research Part C Emerging Technologies, 36, 1-12.

8. Gan, Z., Yang, M., Feng, T., \& Timmermans, H. . (2018). Understanding urban mobility patterns from a spatiotemporal perspective: daily ridership profiles of metro stations. the

9. Hanson, S., \& Huff, J. (1986). Classification issues in the analysis of complex travel behavior. Transportation, 13(3), 271-293.

10. Zhong, C., Batty, M., Manley, E., Wang, J., Wang, Z. , \& Chen, F., et al. (2016). Variability in regularity: mining temporal mobility patterns in London, Singapore, and Beijing using smart-card data. PLOS ONE, 11(2).

11. Primerano, F., Taylor, M. A. P. , Pitaksringkarn, L., \& Tisato, P. (2008). Defining and understanding trip chaining behavior. Transportation, 35(1), 55-72.

12. Saneinejad, S., Roorda, M. J., \& Kennedy, C. (2012). Modeling the impact of weather conditions on active transportation travel behavior. Transportation Research Part D: Transport and Environment, 17(2), 129-137.

13. Agostini, C. A., \& Gastón A. Palmucci. (2008). The anticipated capitalization effect of a new metro line on housing prices. Fiscal Studies, 29.

14. Dorantes, L., Paez, A., \& Vassallo, J. (2011). Analysis of house prices to assess economic impacts of new public transport infrastructure. Transportation Research Record: Journal of the Transportation Research Board, 2245, 131-139.

15. Mejia-Dorantes, L., Paez, A., \& Vassallo, J. M. . (2012). Transportation infrastructure impacts on firm location: the effect of a new metro line in the suburbs of Madrid. Journal of Transport Geography, 22, 236-250.

16. Vuk, G.. (2005). Transport impacts of the Copenhagen metro. Journal of Transport Geography, 13(3), 223-233.

17. Golias, J. C.. (2002). Analysis of traffic corridor impacts from the introduction of the new Athens Metro system. Journal of Transport Geography, 10(2), 0-97.

18. Xiao, F., \& Yu, G. (2018). Impact of a new metro line: analysis of metro passenger flow and travel time based on smart card data. Journal of Advanced Transportation, 2018, 1-13.

19. Wang, Z.. (2014). Passenger Flow Prediction Model of the Newly Constructed Urban Rail Transit Line. 2014 International Conference of Logistics Engineering and Management.

20. Liu, S., Yao, E., \& Li, B. . (2018). Exploring urban rail transit station-level ridership growth with network expansion. Transportation Research Part D Transport and Environment.73, 391-402

21. B. Wang: Theory and Application for Urban Rail Transit Network Operation (China Communication Press, China, 2014) 